\title{
Risk Assessment for Pathological Fracture After Bone Tumour Biopsy
}

\author{
TADASHI IWAI, MANABU HOSHI, NAOTO OEBISU, KUMI ORITA, \\ AKIYOSHI SHIMATANI, NAOKI TAKADA and HIROAKI NAKAMURA \\ Department of Orthopedic Surgery, Osaka City University Graduate School of Medicine, Osaka, Japan
}

\begin{abstract}
Aim: This study aimed to identify the risk of pathological fractures after bone tumour biopsy. Materials and Methods: Fifty rabbit femurs were divided into groups according to defect size: Control (no defect), type 1 (10\% width), type 2 (20\% width), type 3 (30\% width), and type 4 (40\% width). Another 20 were also divided into control, type A (27\% length), type B (40\% length), and type C $(53 \%$ length) groups. Performing femoral head compression testing allowed each parameter (maximum load, displacement, elastic modulus, and fracture energy) to be calculated individually. Results: Compressive maximum load was significantly higher for type 1 than for the other types when testing rectangular defects of different widths, while there were no significant differences between the three types when testing by defect length. Conclusion: It may be useful for orthopaedic oncologists to make a rectangular biopsy hole with a width measuring less than $10 \%$ of the circumference and to enlarge the hole longitudinally to avoid pathological fracture.
\end{abstract}

Bone tumours are relatively uncommon and comprise a wide variety of histological types depending on whether they are benign, malignant, or intermediate $(1,2)$. Orthopaedic surgeons usually require a pathological diagnosis to determine the treatment strategy, particularly in cases where a malignant bone tumour is suspected. The requisite biopsy procedure involves the creation of a biopsy hole in the cortex wall of the affected bone, from which a piece of the tumour tissue (sample) is obtained (3). However, this procedure may

This article is freely accessible online.

Correspondence to: Tadashi Iwai, Department of Orthopedic Surgery, Osaka City University Graduate School of Medicine, 1-43 Asahi-Machi, Abeno-Ku, Osaka 545-8585, Japan. E-mail: qq329xpd@opal.ocn.ne.jp

Key Words: Bone neoplasm, femur, orthopaedics, osteotomy, New Zealand White rabbits. result in severe complications, including copious bleeding, expansion of malignant tumour contamination, and risk of pathological fracture due to weakening of the bone $(3,4)$. In Japan, the surgical procedure is typically determined based on the new Katagiri score for the following factors: Primary site, Eastern Cooperative Oncology Group performance status before fracture, the degree of bone destruction, general complications, multiple bone metastases at other sites, prior treatment with chemotherapy, and a history of visceral metastasis (5). Regarding bone destruction, in 1981, Mirels et al. proposed a scoring system for the prediction of fracture wherein the location and size of bone metastasis, several radiographic factors, and the degree of pain were assessed (6). Furthermore, there have been reports about significant risk factors for pathological fracture due to bone metastases $(7,8)$.

However, a few reports have discussed bone strength following bone biopsy, and there have been only minimal experimental investigations using human cadavers or animal bone models (9). It is essential to reduce the risk of pathological fracture resulting from a bone biopsy procedure. The optimal shape for a bone tumour biopsy has been shown to be rectangular (10). Although a relationship between the width of the biopsy opening and the fragility of the affected bone has been suspected, no threshold associated with the prevention of pathological fracture has been set. Therefore, we hypothesized that the wider the biopsy opening, the more fragile the affected bone would be.

The purpose of this study was to quantify geometrical factors of rectangular biopsy holes (width and length) associated with the risk for pathologic fracture after bone tumour biopsy, using the rabbit femoral head compression test.

\section{Materials and Methods}

Animals. Fifty female New Zealand White rabbits aged 1-2 years and weighing between 3500-4500 g were purchased from SLC Japan (Shizuoka, Japan) and housed individually, with free access to food and water. They were euthanised with an overdose of intravenously administered sodium pentobarbitone $(800 \mathrm{mg} / \mathrm{kg})$, and their hind limbs were dissected. After the creation of defects 
according to experiments below, the femurs underwent femoral head compression testing as described below. This study was approved by our Institutional Review Board (no. 17031).

Experiment 1 . The femur specimens were kept in a freezer at $-20^{\circ} \mathrm{C}$ for 2 weeks after harvesting and stored in a saline solution prior to the test. Before mechanical testing, the femurs were removed from frozen storage and saturated in tepid saline while keeping them moist.

Based on a previous study, we decided that the location of bone fenestration should be the femoral shaft (10). A Stryker Total Performance System high-speed drill (Stryker Instruments, Kalamazoo, MI, USA) with a diamond burr, set at 60,000 rpm, was used to create holes in the bone. The femurs were randomly assigned to four groups with 10 samples each. Each group included a rectangular hole artificially created on the femoral shaft, all of the same length and at the same site but of four different widths. Each diagonal intersection of these holes was situated at $1.5 \mathrm{~cm}$ distal to the lesser trochanter on the front surface of the femoral shaft. Type 1 was $2.6-3.0 \mathrm{~mm} \times 12 \mathrm{~mm}$ ( $10 \%$ of the circumference); type 2 was 5.2-6.0 $\mathrm{mm} \times 12 \mathrm{~mm}$ (20\% of the circumference); type 3 was a 7.8$9.0 \mathrm{~mm} \times 12 \mathrm{~mm}(30 \%$ of the circumference); and type 4 was $10.4-$ $12.0 \mathrm{~mm} \times 12 \mathrm{~mm}$ (40\% of the circumference) (Figure 1A).

Experiment 2. Before mechanical testing, both femurs were removed from frozen storage and saturated in tepid saline for the bone to be drilled while keeping the femur moist. The drill and calibration used to create holes in the bones were similar to those in experiment 1 . The femurs were assigned to three groups, with each group comprising 10 samples. The three groups included three types of artificially created, rectangular defect of the same width at the same site on the femoral shaft but of three different lengths. These holes were all centered around $1.5 \mathrm{~cm}$ distal to the lesser trochanter on the front surface of the femoral shaft. Type A was 2.6$3.0 \mathrm{~mm} \times 12 \mathrm{~mm}(10 \%$ of the circumference $\times 27 \%$ of the diaphyseal length); type B was 2.6-3.0 $\mathrm{mm} \times 18 \mathrm{~mm}(10 \%$ of the circumference $\times 40 \%$ of the diaphyseal length); and type $\mathrm{C}$ was a $2.6-3.0 \mathrm{~mm} \times 24 \mathrm{~mm}(10 \%$ of the circumference $\times 53 \%$ of the diaphyseal length) (Figure 1B).

Femoral head compression test. The femoral head compression test was conducted using EZ Graph software (Shimadzu Corp., Kyoto, Japan). The test was set up using upper and lower jigs and a cylindrical holder, oriented such that the femur was vertical in the sagittal plane, valgus in the frontal plane, and slightly extroverted in the coronal plane. The lower part of the femur was completely fixed in a polyvinyl chloride pipe using epoxy resin. The upper jig in contact with the femoral head was designed to be flat; it was designed such that any interference with the femur diaphysis during the compression test was avoided (Figure 1C).

A compression load was then applied at a rate of $10 \mathrm{~mm} / \mathrm{min}$. The compression direction was parallel to the mechanical axis, and the compression test was performed until the femur specimens fractured. The magnitude of the applied load and displacement was continuously recorded. From the test results, maximum load (N), displacement $(\mathrm{mm})$, elastic modulus $\left(\mathrm{N} / \mathrm{mm}^{2}\right)$, and fracture energy $(\mathrm{N} \cdot \mathrm{mm})$ were calculated (Figure 1D). Elastic modulus was calculated between $20 \%$ and $80 \%$ of the maximum fracture load using the load-displacement curve.

The maximum load was the maximum value of loading increase during the mechanical testing. A maximum load indicates more difficulty in fracturing the femur. Displacement was the distance travelled by the femoral head between the start of the experiment and the moment of fracture. A larger displacement indicates more difficulty in fracturing the femur, i.e. it was easy to bend. The elastic modulus is strongly correlated with stiffness, so that the numerical value of the elastic modulus is a measure of the material's rigidity. Fracture energy was equal to the area under the load-displacement curve. Larger fracture energy values indicate more difficulty in fracturing the femur.

Statistical analysis. Data were analysed using the Kruskal-Wallis test. The Steel-Dwass test for multiple comparisons was performed to compare the groups within each experimental set-up in terms of the following four parameters: maximum load, displacement, elastic modulus, and fracture energy. Statistical analysis was performed using the Excel statistical software package (Ekuseru-Toukei 2015; Social Survey Research Information Co., Ltd., Tokyo, Japan) for Windows, and $p$-values less than 0.05 were considered statistically significant.

\section{Results}

Experiment 1. The median maximum compressive load $(\mathrm{N})$ of each group recorded during mechanical testing was as follows: Control (no defect) $=638.0$, type $1 \quad(10 \%$ width $)=590.3$, type $2(20 \%$ width $)=227.8$, type $3(30 \%$ width $)=158.8$, and type 4 (40\% width $)=133.9$ (Figure 2$)$. The maximum compressive load of type 1 was significantly higher than that of types $2(p=0.006), 3(p=0.0026)$, and 4 $(p=0.002)$ (Figure 2). No significant difference was observed between the maximum compressive loads of the control (no defect) and type 1 ( $p=0.991$, Figure 2$)$.

The median displacements of the groups were 2.375, $2.172,1.174,0.869$, and $0.997 \mathrm{~mm}$, respectively (Figure 2). The displacement of type 1 was significantly higher than that of types $2(p=0.01), 3(p=0.006)$, and $4(p=0.03)$ (Figure 2). No significant difference was observed between the displacements of the control and type $1(p=0.7$, Figure 2).

The median elastic modulus of the control, type 1 , type 2 , type 3 , and type 4 groups were 34,116.5, 33,649.1, 19,907.2, $24,810.0$, and $24,122.9 \mathrm{~N} / \mathrm{mm}^{2}$, respectively (Figure 2). No significant differences were observed between the control and other groups ( $p=0.068$, Figure 2$)$.

The median fracture energies were 995.82, 604.25, 134.09, 74.304, and 52.421 N mm, respectively (Figure 2). The fracture energy of type 1 was significantly higher than that of types $2(p=0.008), 3(p=0.003)$, and $4(p=0.002)$ (Figure 2$)$. No significant differences were observed between the fracture energies of the control and type $1(p=0.092$, Figure 2$)$.

Experiment 2. The median maximum compressive loads of the control, type A (12 mm length, 27\%), type B (18 mm length, 40\%), and type C (24 mm length, 53\%) groups recorded during mechanical testing were 638.0, 590.3, 495.9, and $421.1 \mathrm{~N}$, respectively (Figure 3). No significant 


\section{A Control Type 1 Type 2 Type 3 Type 4}
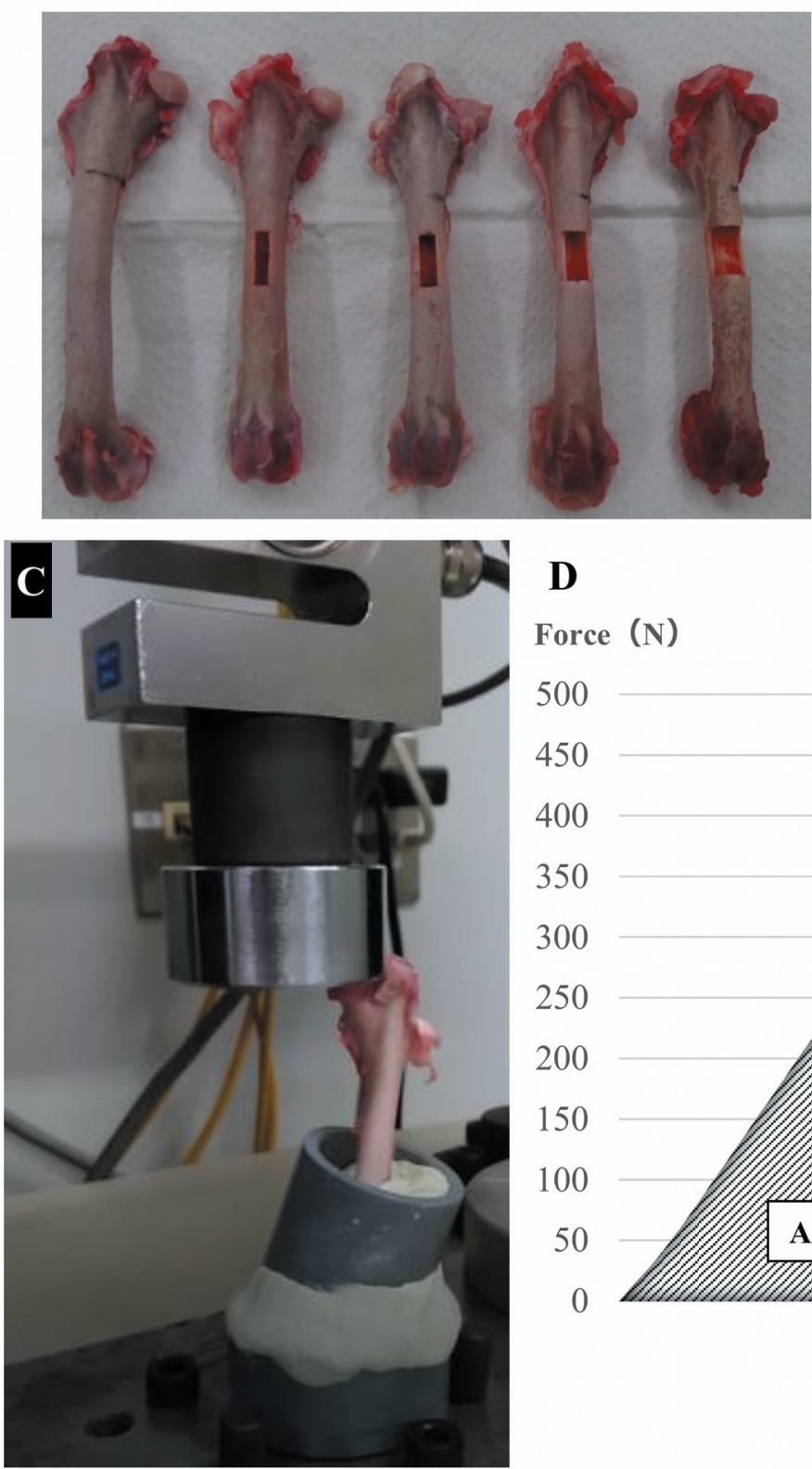

D

\section{B Control Type A Type B Type C}
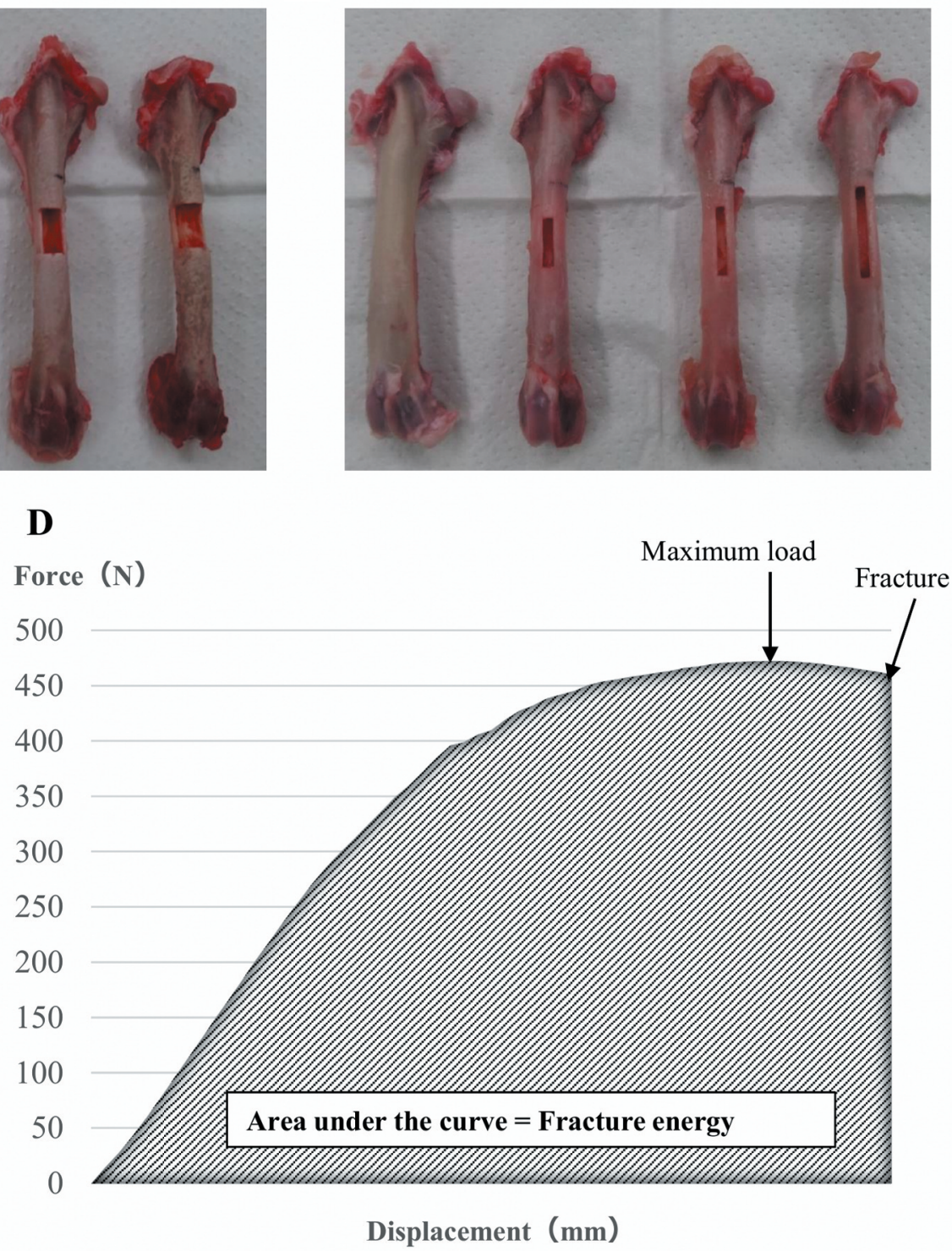

Figure 1. Femoral head compression test. A: Representative specimens showing the artificially created bone biopsy hole in the different groups of experiment 1: Control, no defect; type 1, 10\% width of the circumference; type 2, 20\% width; type 3, 30\% width; type 4, 40\% width. B: Representative specimens showing the artificially created bone biopsy hole in groups of experiment 2: Control, no defect; type A, 12 mm length (27\% of the diaphyseal length); type B, $18 \mathrm{~mm}$ length (40\%); type C, $24 \mathrm{~mm}$ length (53\%). C: The compression direction was parallel to the mechanical axis. D: The compression test was completed when the femur specimen fractured. A load-displacement curve of the extrinsic properties of a specimen is shown. The main parameters derived from these measurements are maximum load $(N)$, displacement (mm), elastic modulus $\left(N / m m^{2}\right)$, and fracture energy ( $N$ mm).

differences were observed between the control and other groups ( $p=0.06$, Figure 3).

The median displacements were $2.375,2.172,1.659$, and $1.556 \mathrm{~mm}$, respectively (Figure 3). The displacement of types $\mathrm{B}$ and $\mathrm{C}$ was significantly lower than that of the control ( $p=0.005$ and $p=0.02$, respectively; Figure 3 ).

The median elastic moduli were $34,116.5$, 33,649.1, $39,647.2$, and 25,712.1 N/mm2, respectively (Figure 3). No 
significant differences were observed between the control and the other groups ( $p=0.1$, Figure 3 ).

The median fracture energies were 995.82, 604.25, 358.33, and $300.73 \mathrm{~N} \mathrm{~mm}$, respectively (Figure 3). The fracture energy of types $\mathrm{B}$ and $\mathrm{C}$ was significantly lower than that of the control $(p<0.001$ and $p=0.001$, respectively, Figure 3). No significant difference was observed between type A, B, or type C $(p=0.27, p=0.17$, and $p=0.95$, respectively, Figure 3 ).

\section{Discussion}

Biopsy is a key tool in definitive diagnosis and is especially valuable in patients who may have single bone metastasis or abnormal radiological characteristics that are suggestive of malignant bone tumours (3). Orthopaedic surgeons often make a biopsy hole in the cortical wall of the affected bone to obtain pieces of tumour tissue. However, in some cases, this procedure itself may be a risk factor of weakening the bone (3). Pathological fracture of fragile bone results in tumour contamination, particularly if the tumour is malignant (3). It is challenging to define radiologically the surgical margin safely; therefore, more curative margins of safety tissues, including the tumour, should be sacrificed $(11,12)$. Moreover, physical performance would be reduced after surgical treatment of pathological fracture in malignant tumours; thus, pathological fractures adversely affect quality-of-life outcomes (13). A close relationship between pathological fracture and poor survival rates of patients has been reported (13). The rate of local recurrence in patients with pathological fracture was significantly higher than that in those without; this may explain the poorer survival in patients with pathological fracture (13). Furthermore, fractures after treatment similarly have negative effects, even if the bone tumour was benign (14). Therefore, biopsy should be conducted safely as far as possible. However, there are a few reports of experimental investigations of bone tumour biopsy for avoiding pathological fractures. Clerk et al., in 1977, indicated the mechanism underlying the relation between the shape of the biopsy hole and bone strength (8).

A previous study showed that the optimal shape of the bone tumour biopsy hole using the rabbit femoral head compression test was a rectangle with a narrow width (10). However, the study was unable to validate the concrete numerical value associated with the reduction in fracture risk. Therefore, in this investigation, we made a biopsy hole in the cortical wall of the rabbit femur and employed the rabbit femoral head compression test to identify the optimal width and length of bone tumour biopsy hole.

Regarding the maximum load and fracture energy in experiment 1 , no significant difference was observed between the control and type 1, while the bone strength of a femur with a hole more than $20 \%$ width was significantly lower than that of the control (Figure 2). Moreover, the maximum load and fracture energy of type 1 were also significantly higher than that of the other experimental types, whilst no significant difference was observed between types 2, 3, and 4 .

Displacement of the femur with a hole more than $20 \%$ in width was also significantly lower than that of a femur without a defect. In our study, the displacement of type 2 was approximately half that of the control. No significant differences were observed among the groups regarding the elastic modulus, suggesting that the presence of a structural defect, such as a biopsy hole, in a femur did not cause significant impairment compared to a femur without a defect. Therefore, it was concluded that the rigidity of the rabbit femur was maintained after artificially making the biopsy hole in experiment 1 .

In experiment 2 , no significant difference was observed in the maximum load of a femur with a hole and that of a femur without defect (Figure 3). Displacement and fracture energy of a femur with a type $\mathrm{B}$ or $\mathrm{C}$ hole were significantly lower than that of a femur without a defect, whilst there were no significant differences in the elastic modulus. Therefore, the data from experiment 2 verified that the maximum load of the rabbit femur was maintained even after creation of rectangular holes, and that increasing the lengths of these holes, up to a maximum length of $24 \mathrm{~mm}$ (53\% of the diaphyseal length), did not alter this finding.

Based on the above results, the decrease in bone strength concerning the width of a defect is not predicted in a straight-line graph; however, it is rather revealed by a sharp decrease if the width of the bone defect is more than $10 \%$ of the circumference (Figure 2). Regarding defect length, bone strength may be somewhat maintained, even if the length of the bone defect is just over $50 \%$ of the diaphyseal length (Figure 3).

This study has several limitations. Ideally, human cadavers should have been used instead of animal bones based on clinical grounds. Moreover, a bone biopsy is often performed on the lateral side of the femoral bone in clinical settings. Therefore, experimental holes should have been made in the same areas on the lateral side of the rabbit femurs. However, it was challenging to make an accurate biopsy hole in the cortex wall on the lateral side because of the extremely narrow surface of the bone; therefore, we made the hole in the anterior side, on the wide surface. Based on our previous study regarding the shape of the biopsy hole, we made only rectangular holes in this study (10). Clerk et al. indicated that a rectangular hole with rounded ends was optimal regarding bone strength (9). Further studies investigating the notch factor are warranted; however, it is better to perform bone tumour biopsy quickly because of concerns regarding tumour contamination and a large amount of blood loss, which could render the creation of a rectangular hole with rounded ends difficult on clinical grounds. Furthermore, we should have 


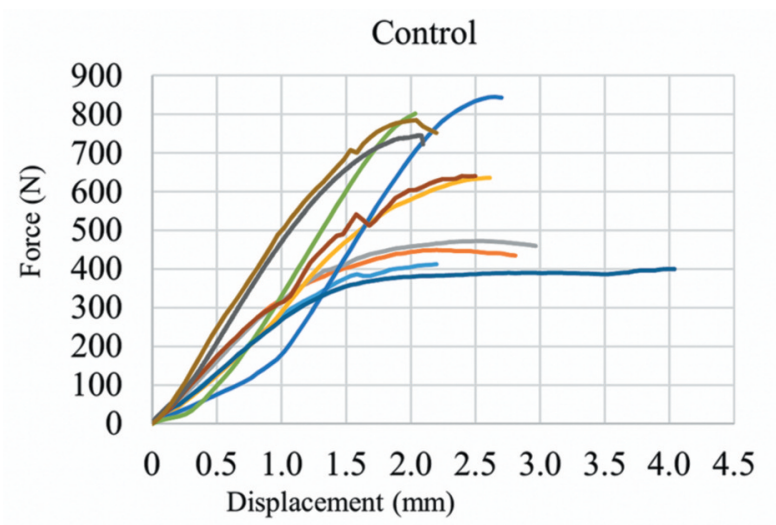

Type 2 (20\% width)
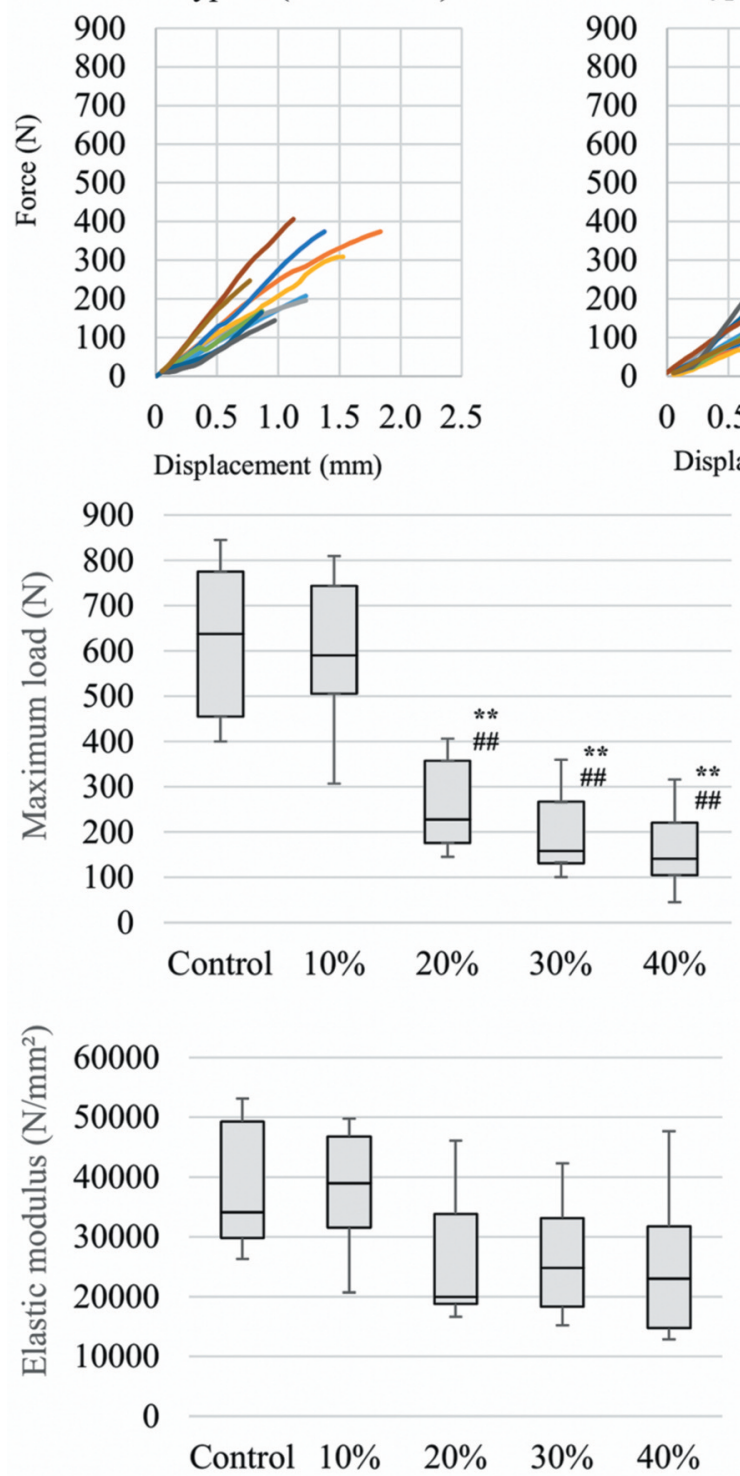

Type 1 (10\% width)

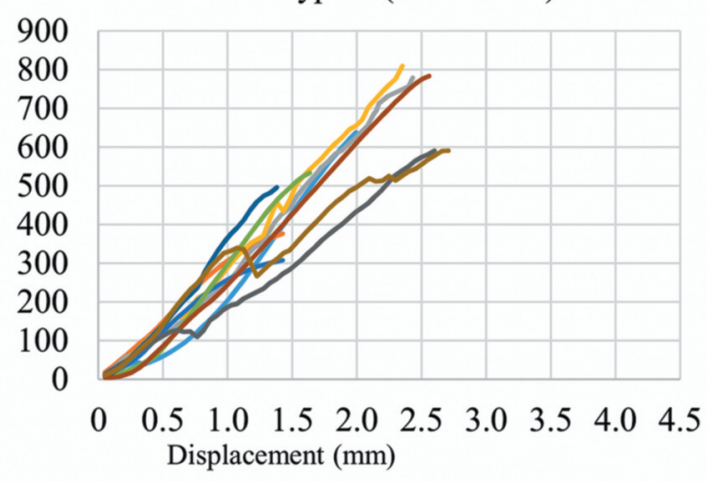

Type 3 (30\% width)

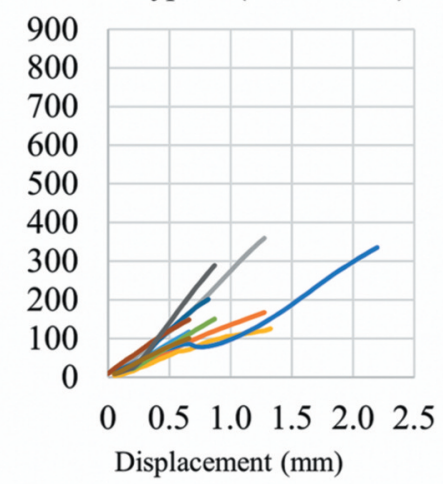

Type 4 ( $40 \%$ width)

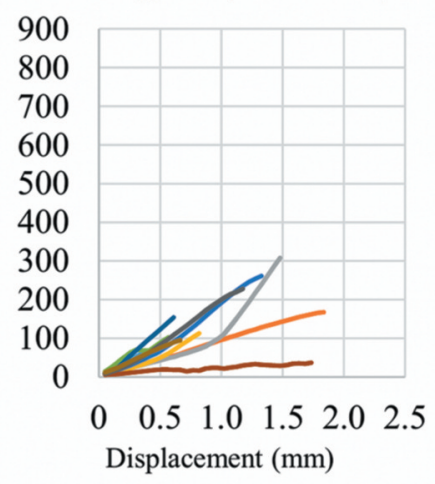

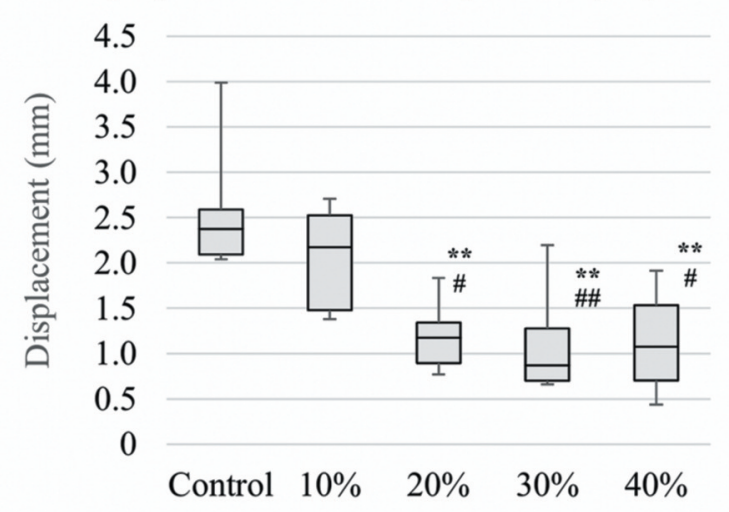

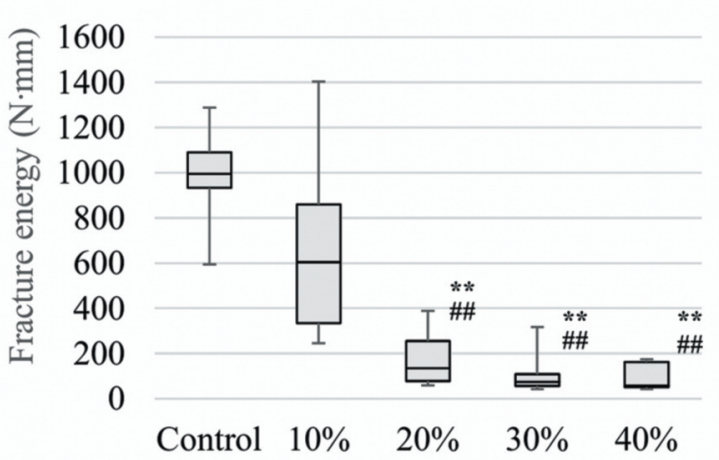

Figure 2. Load-displacement curves of each femur in the femoral head compression test for groups of experiment 1 with different defect widths as a percentage of the circumference: Control, no defect; type 1, 10\% width; type 2, 20\% width; type 3, 30\% width; and type 4, 40\% width. The distributions of maximum load, displacement, elastic modulus, and fracture energy are shown. Significantly different at: $* * p<0.01$ vs. control; ${ }^{\#} p<0.05,{ }^{\#} p<0.01$ vs. type 1 . 


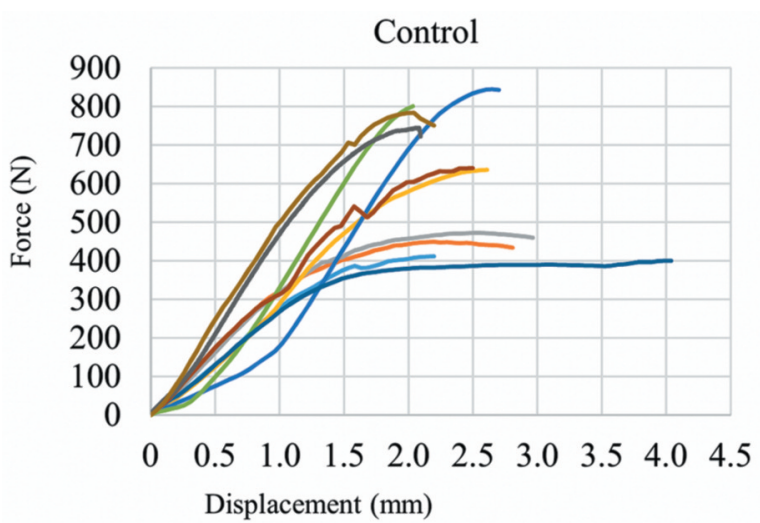

Type B (18mm length, 40\%)
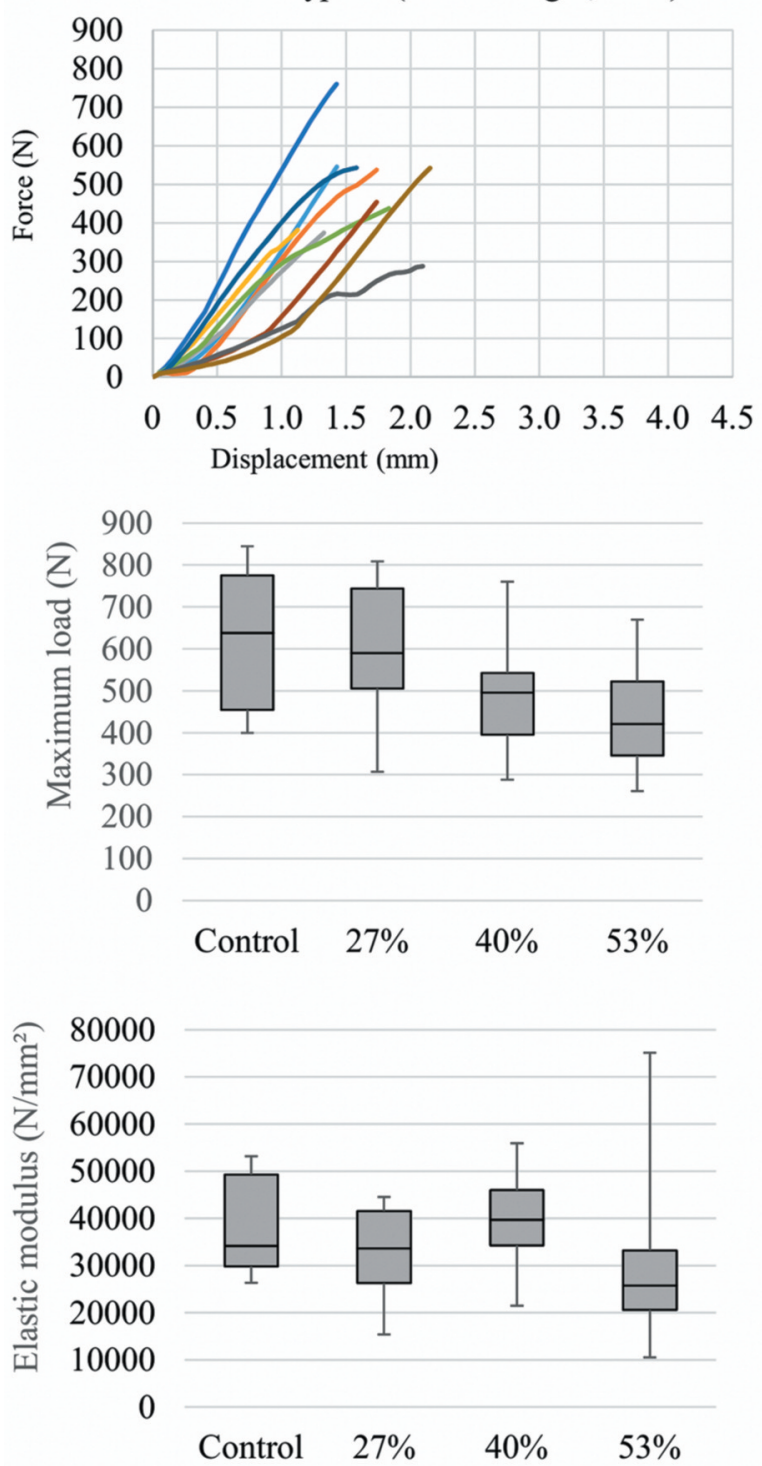

Type A (12mm length, 27\%)

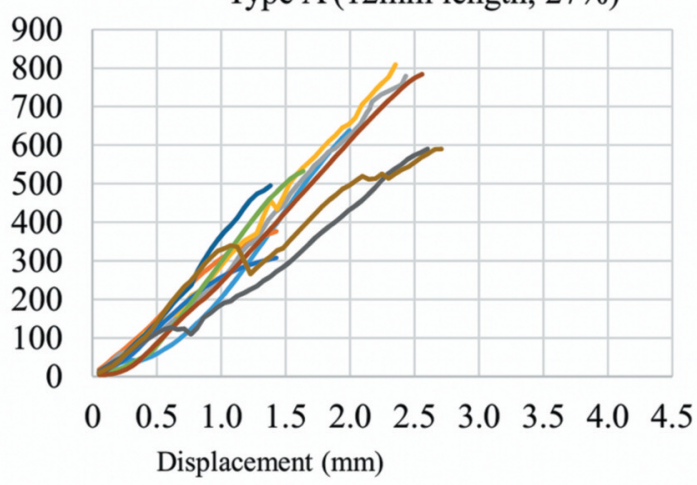

Type C (24mm length, 53\%)
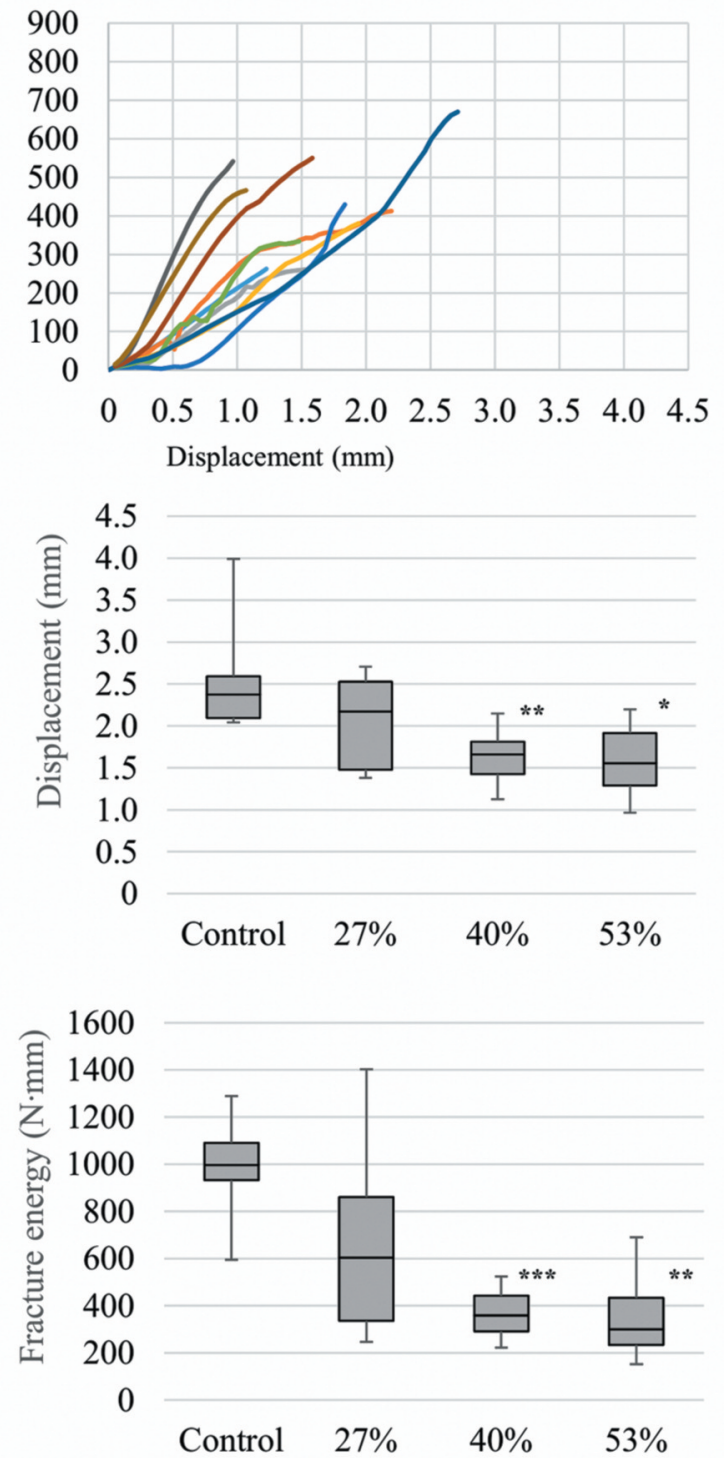

Figure 3. Load-displacement curves of each femur in the femoral head compression test for groups of experiment 2 with different defect lengths as a percentage of diaphyseal length: Control, no defect; type A, $12 \mathrm{~mm}$ length (27\%); type B, $18 \mathrm{~mm}$ length (40\%); and type C, $24 \mathrm{~mm}$ length (53\%). The distributions of maximum load, displacement, elastic modulus, and fracture energy are shown. Significantly different at: $* p<0.05$, $* * p<0.01$, $* * * p<0.001$ vs. control. 
examined the effect of temperature on creating holes. A previous report indicated that the heat generated by creating a larger hole would considerably weaken the affected bone compared to that for a small hole (15). A further limitation is the differences between humans and rabbits because rabbits are quadrupeds, while humans are bipeds. These disparities imply that the results of animal experiments are not always related to those in humans. The most crucial limitation was that only the results of the femoral head compression test were applied to verify the data. The data of the torsion test should have been added to obtain more comprehensive results. Similarly, we should have considered the cortical thickness (inner and outer diameter) and the bone quality (mass, micro-structure, density) as risk factors for fracture. Regarding the cortical thickness, Clerk et al. demonstrated that there was no significant change in the amount of bone removed in the same cross section (9). However, it was extremely difficult for us to conduct a mechanical test, including these risk factors for fracture.

In conclusion, this study quantified the geometrical factors of rectangular biopsy holes (width and length) associated with pathological fracture after bone tumour biopsy using a rabbit femoral shaft biopsy model. To minimise the risk of fracture, it may be useful for orthopaedic oncologists to make a rectangular biopsy hole with a width measuring less than $10 \%$ of the circumference, in the cortex wall. Furthermore, it may be important to fairly enlarge the biopsy hole longitudinally (just over $50 \%$ of the diaphyseal length) to obtain sufficient quantities of tumour tissue.

\section{Conflicts of Interest}

The Authors declare that they have no known competing financial interests or personal relationships that could have appeared to influence the work reported in this article.

\section{Authors' Contributions}

Tadashi Iwai designed this study, analysed the data, prepared the figures and wrote original draft. Manabu Hoshi and Hiroaki Nakamura oversaw the study and revised the article. All Authors reviewed the article.

\section{Acknowledgements}

The Authors are very grateful for the invaluable support and various discussions with other members of the Department of Orthopaedic Surgery.

\section{References}

1 Fletcher CDM, Bridge JA, Hogendoorn PCW and Mertens F: WHO Classification of Tumours of Soft Tissue and Bone. Fourth Edition. IARC Press, 2013.

2 Sugiyama H, Omonishi K, Yonehara S, Ozasa K, Kajihara H, Tsuya $\mathrm{T}$ and Takeshima $\mathrm{Y}$ : Characteristics of benign and malignant bone tumors registered in the Hiroshima Tumor Tissue Registry, 1973-2012. JB JS Open Access 3: e0064, 2018. PMID: 30280138. DOI: 10.2106/JBJS.OA.17.00064

3 Traina F, Errani C, Toscano A, Pungetti C, Fabbri D, Mazzotti A, Donati D and Faldini C: Current concepts in the biopsy of musculoskeletal tumors: AAOS exhibit selection. J Bone Joint Surg Am 97: e7, 2015. PMID: 25609446. DOI: 10.2106/ JBJS.N.00661

4 Casali PG, Bielack S, Abecassis N, Aro HT, Bauer S, Biagini R, Bonvalot S, Boukovinas I, Bovee JVMG, Brennan B, Brodowicz T, Broto JM, Brugières L, Buonadonna A, De Álava E, Dei Tos AP, Del Muro XG, Dileo P, Dhooge C, Eriksson M, Fagioli F, Fedenko A, Ferraresi V, Ferrari A, Ferrari S, Frezza AM, Gaspar N, Gasperoni S, Gelderblom H, Gil T, Grignani G, Gronchi A, Haas RL, Hassan B, Hecker-Nolting S, Hohenberger P, Issels R, Joensuu H, Jones RL, Judson I, Jutte P, Kaal S, Kager L, Kasper B, Kopeckova K, Krákorová DA, Ladenstein R, Le Cesne A, Lugowska I, Merimsky O, Montemurro M, Morland B, Pantaleo MA, Piana R, Picci P, Piperno-Neumann S, Pousa AL, Reichardt P, Robinson MH, Rutkowski P, Safwat AA, Schöffski P, Sleijfer S, Stacchiotti S, Strauss SJ, Sundby Hall K, Unk M, Van Coevorden F, van der Graaf WTA, Whelan J, Wardelmann E, Zaikova $\mathrm{O}$ and Blay JY; ESMO Guidelines Committee, PaedCan and ERN EURACAN: Bone sarcomas: ESMO-PaedCanEURACAN Clinical Practice Guidelines for diagnosis, treatment and follow-up. Ann Oncol 29(Suppl_4): 79-95, 2018. PMID: 30285218. DOI: $10.1093 /$ annonc/mdy310

5 Katagiri H, Okada R, Takagi T, Takahashi M, Murata H, Harada $\mathrm{H}$, Nishimura $\mathrm{T}$, Asakura $\mathrm{H}$ and Ogawa $\mathrm{H}$ : New prognostic factors and scoring system for patients with skeletal metastasis. Cancer Med 3: 1359-1367, 2014. PMID: 25044999. DOI: $10.1002 / \mathrm{cam} 4.292$

6 Mirels H: Metastatic disease in long bones. a proposed scoring system for diagnosing impending pathologic fractures. Clin Orthop Relat Res 249: 256-264, 1989. PMID: 2684463. DOI: 10.1097/00003086-198912000-00027

7 Van der Linden YM, Dijkstra PD, Kroon HM, Lok JJ, Noordijk EM, Leer JW and Marijnen CA: Comparative analysis of risk factors for pathological fracture with femoral metastases. J Bone Joint Surg Br 86: 566-573, 2004. PMID: 15174555.

8 Tatar Z, Soubrier M, Dillies AF, Verrelle P, Boisgard S and Lapeyre M: Assessment of the risk factors for impending fractures following radiotherapy for long bone metastases using CT scanbased virtual simulation: A retrospective study. Radiat Oncol 9: 227, 2014. PMID: 25319635. DOI: 10.1186/s13014-014-0227-1

9 Clark CR, Morgan C, Sonstegard DA and Matthews LS: The effect of biopsy-hole shape and size on bone strength. J Bone Joint Surg Am 59: 213-217, 1977. PMID: 845207. DOI: 10.2106/00004623-197759020-00014

10 Iwai T, Hoshi M, Oebisu N, Orita K, Shimatani A, Takada N and Nakamura $\mathrm{H}$ : Exploration of the optimal shape for bone tumour biopsy. Anticancer Res 39: 4191-4197, 2019. PMID: 31366505. DOI: 10.21873/anticanres.13579

11 Kawaguchi N, Ahmed AR, Matsumoto S, Manabe J and Matsushita Y: The concept of curative margin in surgery for bone and soft tissue sarcoma. Clin Orthop Relat Res 419: 165172, 2004. PMID: 15021149. DOI: 10.1097/00003086-200402 000-00027

12 Willeumier JJ, van der Linden YM, van de Sande MAJ and Dijkstra PDS: Treatment of pathological fractures of the long 
bones. EFORT Open Rev 1: 136-145, 2017. PMID: 28461940. DOI: $10.1302 / 2058-5241.1 .000008$

13 Kelley LM, Schlegel M, Hecker-Nolting S, Kevric M, Haller B, Rössig C, Reichardt P, Kager L, Kühne T, Gosheger G, Windhager R, Specht K, Rechl H, Tunn PU, Baumhoer D, Wirth T, Werner M, von Kalle T, Nathrath M, Burdach S, Bielack S and von Lüttichau I: Pathological fracture and prognosis of highgrade osteosarcoma of the extremities: an analysis of 2,847 consecutive Cooperative Osteosarcoma Study Group (COSS) Patients. J Clin Oncol 38: 823-833, 2020. PMID: 31928458. DOI: $10.1200 /$ JCO.19.00827

14 Ruiz Santiago RF, Castellano García Mdel M, Guzmán Álvarez L, Martínez Montes JL, Ruiz García M and Tristán Fernández
JM: Percutaneous treatment of bone tumors by radiofrequency thermal ablation. Eur J Radiol 77: 156-163, 2011. PMID: 19586734. DOI: $10.1016 /$ j.ejrad.2009.06.012

15 Palmisano AC, Tai BL, Belmont B, Irwin TA, Shih A and Holmes JR: Heat accumulation during sequential cortical bone drilling. J Orthop Res 34: 463-470, 2016. PMID: 26334198. DOI: $10.1002 /$ jor.23044

Received December 6, 2020

Revised January 6, 2021

Accepted January 7, 2021 